\title{
Nivolumab-associated acute glomerulonephritis: a case report and literature review
}

\author{
Kyungsuk Jung ${ }^{1 *} \mathbb{D}$, Xu Zeng ${ }^{2}$ and Marijo Bilusic ${ }^{3}$
}

\begin{abstract}
Background: Immune checkpoint inhibitors are changing the landscape of oncology treatment as they are significantly improving treatment for multiple malignancies. Nivolumab, an anti-programmed death 1 antibody, is a US Food and Drug Administration-approved treatment for melanoma, non-small cell lung cancer, and kidney cancer but can result in a spectrum of autoimmune side effects. Adverse effects can occur within any organ system in the body including the colon, lung, liver, endocrine systems, or kidneys.

Case presentation: A 70-year-old male with clear cell kidney cancer was admitted with acute kidney injury while on nivolumab. A kidney biopsy revealed diffuse tubular injury and immune complex-mediated glomerulonephritis. Electron microscopy of the specimen showed hump-like subepithelial deposits. Nivolumab was discontinued and the patient was started on a high dose of steroids. After 5 months of systemic corticosteroids and hemodialysis, the patient's kidney function improved to his baseline level. Despite a prolonged interruption to treatment, immunosuppressive therapy did not compromise the anticancer effects of nivolumab.

Conclusion: Immune-related adverse effects in the kidney can cause autoimmune glomerulonephritis as well as tubulointerstitial injury. In the literature, immune-related nephritis generally responded well to systemic corticosteroid treatment. Based on our experience, a prolonged course of a high dose of steroids and hemodialysis may be required to achieve an adequate treatment effect.
\end{abstract}

Keywords: Immunotherapy, Nivolumab, Renal cell carcinoma, Acute kidney injury, Autoimmune nephritis, Case report

\section{Background}

The field of oncologic immunotherapy is expanding rapidly. Since its introduction into clinical application for the treatment of melanoma [1,2], immunotherapy has been studied in numerous trials for other types of cancer. Although treatments appear promising, immune checkpoint inhibition is associated with a unique category of side effects, termed immune-related adverse events (irAE) [3].

Programmed death 1 (PD1) is a transmembrane protein expressed on T cells, B cells, and natural killer cells. It binds to PD ligand 1 (PDL1) on the cell surface of tumor cells, inhibits cancer cell apoptosis, and downregulates the functions of $\mathrm{T}$ cells $[4,5]$. Nivolumab is a

\footnotetext{
* Correspondence: Kyungsuk.Jung@fccc.edu

'Department of Medicine, Fox Chase Cancer Center, 333 Cottman Ave,

Philadelphia, PA 19111, USA

Full list of author information is available at the end of the article
}

human immunoglobulin (Ig)G4 anti-PD1 monoclonal antibody, designed to augment an immunologic reaction against cancer cells. The medication is currently US Food and Drug Administration-approved for patients with advanced melanoma, non-small cell lung cancer, and renal cell carcinoma. irAE caused by nivolumab can affect any organ system including the lung, colon, liver, endocrine, kidney, skin, and brain. Grade 3 or 4 kidney injury was reported in $2 \%$ of the patients with renal cell carcinoma who were treated with nivolumab (creatinine $>3$ times above baseline or $>4.0 \mathrm{mg} / \mathrm{dL}$, or lifethreatening consequences requiring dialysis) [6].

Kidney injury can cause diverse sequelae and potentially limit further oncologic treatment options, necessitating close follow-up and treatment. In clinical practice, irAE has been managed by treatment interruption and systemic corticosteroids as the first line, and tumor 
necrosis factor inhibitors or cytotoxic immunosuppressants as the second line [6].

In this report, we present a case of nivolumab-induced glomerulonephritis successfully treated with prolonged use of a high dose of steroids and hemodialysis.

\section{Case presentation}

\section{History and initial presentation}

The patient was a 70-year-old male with a past medical history of oxygen-dependent chronic pulmonary obstructive disease, squamous cell carcinoma of the right vocal cord (treated with definitive radiation therapy in November 1998), and stage 3b chronic kidney disease who was diagnosed with metastatic clear cell renal cell carcinoma in January 2013. Other pertinent past medical history included left renal vein thrombosis for which he was taking enoxaparin. The patient had a history of smoking (120 packs/year) but had quit smoking (120 packs/year) but had quit smoking in January 2013.

For the metastatic renal cell cancer, the patient was started on pazopanib $600 \mathrm{mg}$ daily in February 2013, with a good initial response. However, medication was discontinued in December 2013 because of disease progression in the lungs and rib cage. He then began treatment with nivolumab $3 \mathrm{mg} / \mathrm{kg}$ every 2 weeks in December 2013. His disease initially responded well to the treatment. During the 10-month period while the patient was on nivolumab, left and right kidney tumors decreased by 19 and 13\%, respectively, and adrenal masses decreased by $23 \%$ on both sides. He continued treatment until October 27, 2014 when he was found to have acute kidney injury (AKI), with a creatinine level of $10.08 \mathrm{mg} /$ dL. His serum creatinine level the month prior was $1.67 \mathrm{mg} / \mathrm{dL}$. He was admitted for evaluation and treatment for AKI. At the time of presentation, the patient had symptoms of generalized weakness, fatigue, and loss of appetite. His temperature was $35.7{ }^{\circ} \mathrm{C}$ (tympanic), and his blood pressure and heart rate were 135/ $70 \mathrm{mmHg}$ and 79 beats/min, respectively. He showed a $1.7 \mathrm{~kg}$ weight gain over 1 month and there was the suggestion of $1+$ bilateral ankle edema on physical examination. There was no flank pain or costovertebral angle tenderness.

\section{Hospital course}

Upon admission, a metabolic panel revealed sodium $135 \mathrm{mmol} / \mathrm{L}$, potassium $3.8 \mathrm{mmol} / \mathrm{L}$, chloride $95 \mathrm{mmol} /$ $\mathrm{L}, \mathrm{CO}_{2} 28 \mathrm{mmol} / \mathrm{L}$, total protein $6.1 \mathrm{~g} / \mathrm{dL}$, blood urea nitrogen (BUN) $58 \mathrm{mg} / \mathrm{dL}$, and creatinine $10.08 \mathrm{mg} / \mathrm{dL}$. Urinalysis was positive at $>300 \mathrm{mg} / \mathrm{dL}$ for protein and $3+$ for hemoglobin. On microscopic examination of urine, there were too-numerous-to-count red blood cells, 3-5 white blood cells, and 1-3 granular casts observed under high-power magnification. Fraction excretion of sodium was 2.2\%. Serum C3 and C4 levels were within normal ranges. Hepatitis $B$ surface antigen, hepatitis $C$ antibody, anti-nuclear antibody, anti-double strand DNA antibody, glomerular basement membrane antibody, cytoplasmic anti-neutrophil cytoplasmic antibody, and perinuclear anti-neutrophil cytoplasmic antibody were all negative. Ultrasound revealed solid masses in the interpolar region of the right kidney and upper pole of the left kidney, representative of his known renal cell carcinoma. Otherwise, kidney sizes were within the normal range and there was no evidence of hydronephrosis.

Biopsy of the right lower pole of the kidney was performed on October 29, 2014. Light microscopic examination demonstrated diffuse tubular injury with vacuoles and immune complex-mediated glomerulonephritis with cellular crescents and necrosis. There was moderate interstitial inflammation with lymphocytes observed. With immunofluorescence, there was diffuse granular mesangial staining for IgA, C3, and kappa and lambda light chains. The specimen was also sent for electron microscopic examination. One glomerulus with severe cellular crescents was selected for examination and demonstrated several hump-like subepithelial deposits and no subendothelial deposits. There was partial podocyte foot process effacement. Proximal tubules were flattened with simplified tubular epithelium and shorter microvilli. Pathologic examinations confirmed the final diagnosis of acute toxic-type tubular injury and IgAdominant acute post-infectious glomerulonephritis. Pictures of microscopic examinations are shown in Fig. 1.

Although there was the possibility of post-infectious glomerulonephritis based on findings of glomerular deposits in the kidney biopsy, the patient did not show symptoms of streptococcal infection such as pharyngitis or a rash prior to admission. The patient's C3 level was normal and he was not hypertensive. Based on patient's previous exposure to nivolumab and lymphocyte infiltration observed in the biopsy, immunotherapy-induced kidney injury was taken into consideration. Nivolumab was discontinued and methylprednisolone administration $40 \mathrm{mg}$ intravenously twice a day was started. The following day, serum potassium increased to $5.6 \mathrm{mmol} / \mathrm{L}$, and creatinine and $\mathrm{BUN}$ were elevated at 11.01 and $63 \mathrm{mg} / \mathrm{dL}$, respectively. Nephrology was consulted and hemodialysis was initiated. Methylprednisolone was increased to $40 \mathrm{mg}$ three times a day (1 $\mathrm{mg} / \mathrm{kg} /$ day). After the biopsy report, the patient was started on pulse dose steroids, methylprednisolone $1 \mathrm{~g}$ intravenously daily for 3 days, followed by methylprednisolone $40 \mathrm{mg}$ intravenously three times a day. The creatinine level decreased after steroid treatment and hemodialysis. Four days later, steroids were changed to oral prednisone $40 \mathrm{mg}$ twice a day and the patient was discharged on steroid treatment and outpatient hemodialysis. On the day of discharge, his creatinine level was $8.80 \mathrm{mg} / \mathrm{dL}$. 


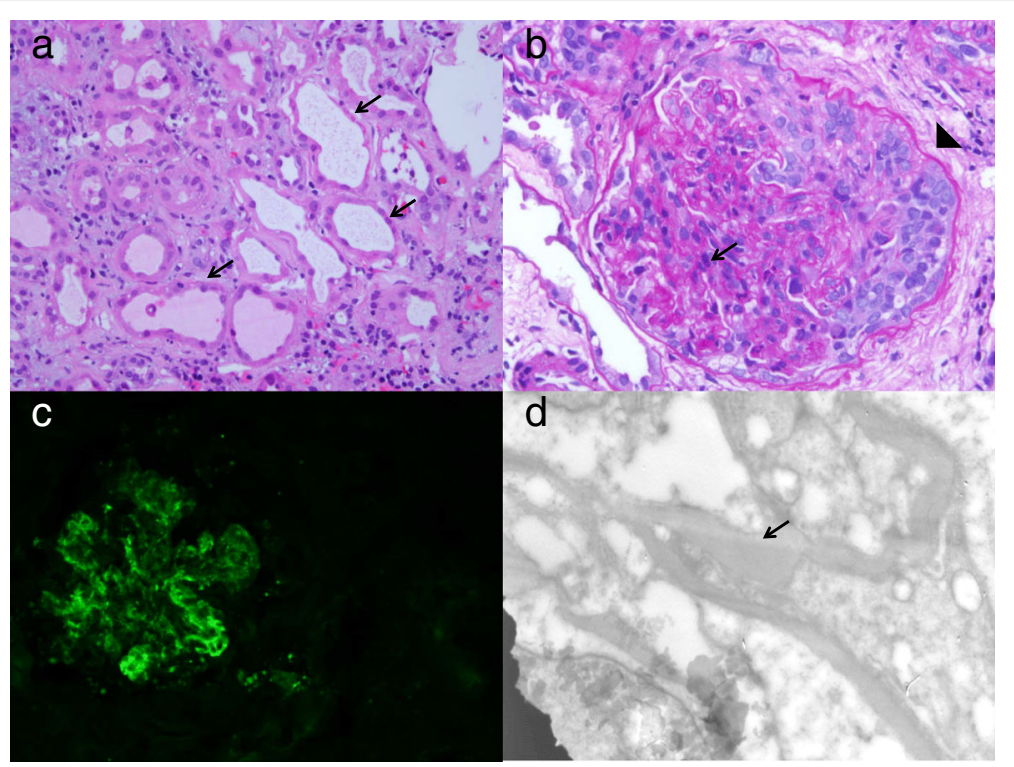

Fig. 1 Microscopic examinations of kidney biopsy specimens. a and $\mathbf{b}$ Hematoxylin and eosin staining of the kidney biopsy specimen revealed interstitial infiltrate with tubular injury (arrows), glomerulonephritis with cellular crescents (arrowhead), and mesangial proliferation (arrow). c Immunofluorescence staining for IgA deposits. d Electron microscopic picture of subepithelial deposit (arrow)

\section{Follow-up and outcome}

One month after discharge, the patient was admitted with a fever, rash, tachycardia, and leukocytosis, consistent with systemic inflammatory response syndrome (SIRS). The source of infection was unclear as blood and urine cultures were negative. The patient had generalized patchy skin lesions with desquamation, most prominent at the bilateral proximal arms and upper torso. Biopsy of skin lesions was deferred, as they were thought to be an irAE and already clinically improving with steroid treatment. The patient was discharged after a short course of intravenous antibiotics. The dose of prednisone was increased at this time. Another month after the second hospitalization, the patient was re-admitted with fever, tachycardia, and hypotension. Again, there was no compelling source of infection identified after an extensive diagnostic work up. During the third hospitalization of 9 days, he received a stress dose of hydrocortisone $100 \mathrm{mg}$ three times a day. Upon discharge, he resumed a tapering course of steroids, starting with prednisone $60 \mathrm{mg}$ daily. The patient tolerated the prolonged course of oral steroids well with no apparent adverse effects. Oral prednisone was stopped at the end of February 2015. In April 2015, his serum creatinine level was $1.81 \mathrm{mg} / \mathrm{dL}$ and BUN was $13 \mathrm{mg} / \mathrm{dL}$. Hemodialysis was discontinued on April 27, 2015. The last contact with the patient was on March 30, 2016 and his kidney function remained stable at the time. Change in serum creatinine over the 6-month treatment period is shown in Fig. 2.
While recovering from nivolumab toxicity, the patient did not receive any treatment for renal cell carcinoma. In spite of the prolonged systemic corticosteroid treatment, anti-tumor activity seemed to continue as the tumors in bilateral kidneys and adrenal glands decreased in sizes for 18 months (left adrenal gland: 3.7 to $2.4 \mathrm{~cm}$, right adrenal gland: 7.0 to $5.8 \mathrm{~cm}$, left kidney mass: 6.0 to $3.4 \mathrm{~cm}$, right kidney mass: 7.0 to $5.8 \mathrm{~cm}$; all measurements in longest diameter). In March 2016, he was started on axitinib $3 \mathrm{mg}$ twice a day for symptomatic disease progression (worsening of rib lesion).

\section{Conclusions}

irAE are encountered more frequently in daily oncologic practice with the increased use of immune checkpoint inhibitors. Immune checkpoint inhibition involves two major transmembrane proteins, cytotoxic T-lymphocyte antigen 4 and PD1. Nivolumab, a monoclonal anti-PD1 antibody, blocks $\mathrm{T}$ cell inhibition and stimulates the immunologic response towards cancer cells, but it may also impair the self-tolerance of the immune system. This potential side effect can occur in any organ of the body but is known to predominately occur in the gastrointestinal tract, lung, liver, and endocrine system [7].

In clinical trials of nivolumab or other anti-PD1 antibodies, the renal system was not affected as frequently as other organ systems. In a population of patients with non-small cell lung cancer, seven of 287 patients (2.4\%) who were treated with nivolumab developed renal injury, but all events were either grade 1 or 2 [8]. Among 


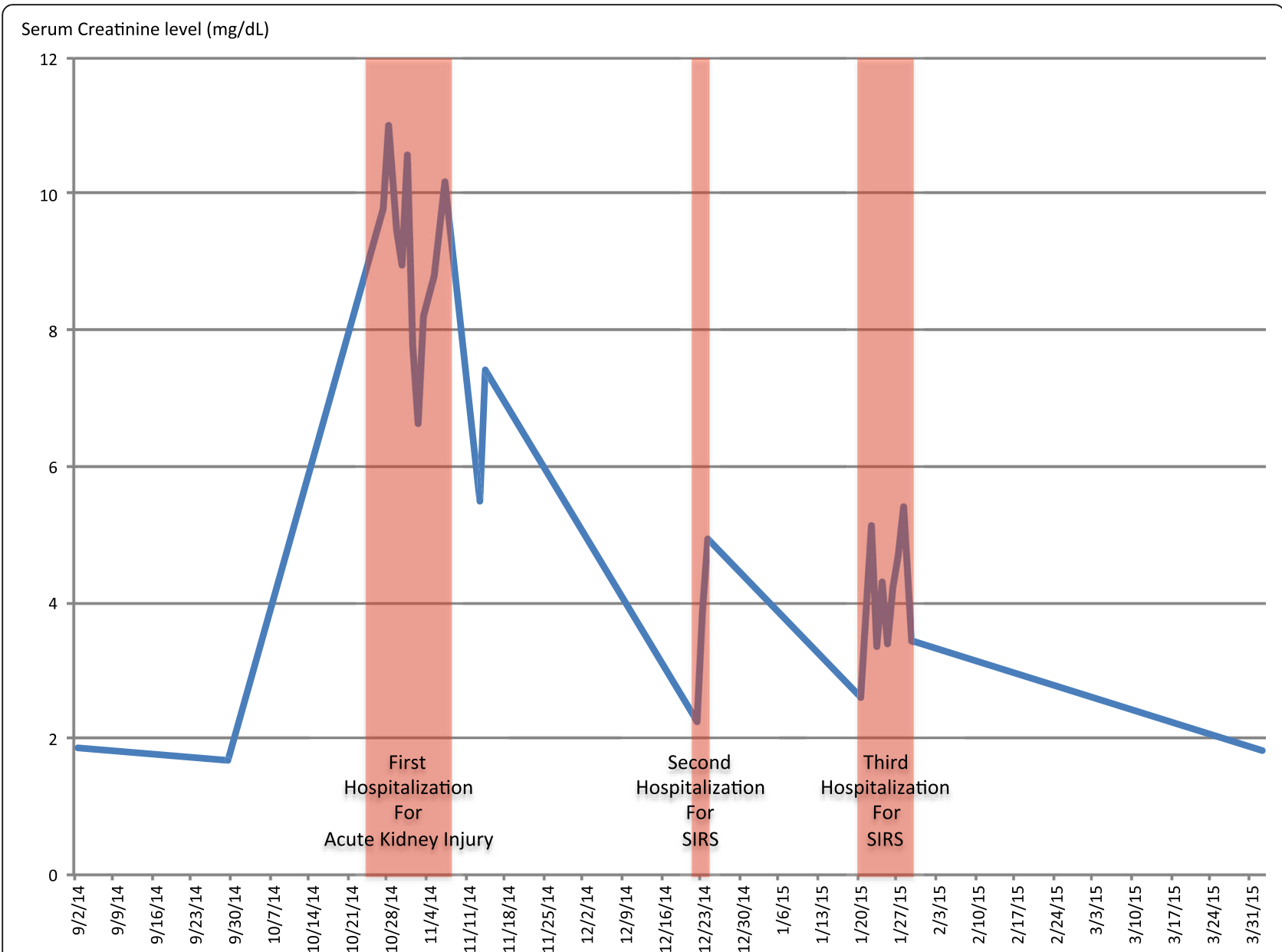

Fig. 2 Serum creatinine changes over the 6-month treatment period

patients with melanoma treated with pembrolizumab (anti-PD1 antibody), one of 277 patients (0.4\%) experienced nephritis with renal failure [9]. Another anti-PD1 antibody, lambrolizumab, was associated with renal failure in three of 135 patients (2\%) with melanoma, with two of these three patients having grade 3 or 4 adverse events [10].

Table 1 summarizes case reports on irAE affecting the kidney, identified in a review of the literature. Fadel et al. reported a case of lupus nephritis that occurred after use of ipilimumab and was resolved after steroid treatment [11]. Six cases of ipilimumab-associated nephritis were reported [12-15]. The articles generally reported successful treatment of ipilimumab-associated nephritis using systemic steroids. In addition, there were three cases of AKI caused by anti-PD1 antibody, such as nivolumab or pembrolizumab. Two patients who had nivolumab-related kidney injury were successfully treated with steroids [16], and one patient who developed pembrolizumab-related kidney injury showed improvement of nephritis after steroid treatment [17].
Although alterations in immunologic self-tolerance theoretically account for renal dysfunction, specific mechanisms among existing case reports are diverse. Biopsy results also varied. One patient was diagnosed with lupus nephritis during treatment with ipilimumab [11]. Diagnosis was made based on the patient being positive for anti-nuclear and anti-double-stranded DNA antibodies. Electron microscopy confirmed the presence of granular, electron-dense extra-membranous deposits. Izzedine et al. reported two cases of acute interstitial nephritis associated with ipilimumab [14]. In a more recent case, reported by Thajudeen et al., a biopsy revealed granulomas and interstitial infiltration with lymphocytes, eosinophils, and plasma cells [15]. In the current case, the biopsy revealed acute tubular injury and immune complex-mediated glomerulonephritis.

Regardless of the etiology or biopsy results, patient's kidney functions generally improved after steroid treatment. We found no case in our review of the literature in which tumor necrosis factor inhibitors or cytotoxic immunosuppressants were required. In some reviewed 
Table 1 Reports in the literature of immunotherapy-associated renal adverse events and treatment

\begin{tabular}{|c|c|c|c|c|c|c|c|c|}
\hline Author & $\begin{array}{l}\text { No. of } \\
\text { patients }\end{array}$ & Age & Gender & Medication & Cancer & Kidney biopsy & Treatment & Outcome \\
\hline $\begin{array}{l}\text { Fadel et al. } \\
\text { [11] } 2009\end{array}$ & 1 & 64 & M & Ipilimumab & Melanoma & $\begin{array}{l}\text { Extra-membranous and mesangial } \\
\text { deposits of immunoglobulin } \\
\text { (consistent with lupus nephritis) }\end{array}$ & Steroids & Resolved \\
\hline $\begin{array}{l}\text { Forde et al. } \\
\text { [12] } 2012\end{array}$ & 1 & 59 & M & Ipilimumab & Melanoma & Not available & $\begin{array}{l}\text { Steroids; no } \\
\text { dialysis }\end{array}$ & Resolved \\
\hline \multirow{2}{*}{$\begin{array}{l}\text { Voskens et al. } \\
\text { [13] } 2013\end{array}$} & 1 & 53 & $F$ & Ipilimumab & Mucosal & Not available & Steroids & Resolved \\
\hline & 2 & 72 & $F$ & Ipilimumab & $\begin{array}{l}\text { Unknown } \\
\text { primary }\end{array}$ & Not available & Steroids & Resolved \\
\hline \multirow[t]{2}{*}{$\begin{array}{l}\text { Izzedine et al. } \\
\text { [14] } 2014\end{array}$} & 1 & 72 & M & Ipilimumab & Melanoma & $\begin{array}{l}\text { Interstitial inflammation and } \\
\text { poly-nuclear infiltration in glomerulus }\end{array}$ & Steroids & Resolved \\
\hline & 2 & 60 & $F$ & Ipilimumab & Melanoma & $\begin{array}{l}\text { Tubulointerstitial inflammation with } \\
\text { necrosis and two non-necrotizing } \\
\text { granulomas }\end{array}$ & Steroids & Resolved \\
\hline $\begin{array}{l}\text { Thajudeen et al. } \\
\text { [15] } 2015\end{array}$ & 1 & 74 & M & Ipilimumab & Melanoma & $\begin{array}{l}\text { Interstitial edema with infiltrate of } \\
\text { lymphocytes and granulomas }\end{array}$ & Steroids & $\begin{array}{l}\text { Resolved; } \\
\text { ipilimumab } \\
\text { resumed }\end{array}$ \\
\hline $\begin{array}{l}\text { Vandiver et al. } \\
\text { [16] } 2016\end{array}$ & 1 & 58 & $\mathrm{~F}$ & Nivolumab & Melanoma & Not available & Steroids & Resolved \\
\hline \multirow[t]{2}{*}{$\begin{array}{l}\text { Hofmann et al. } \\
\text { [17] } 2016\end{array}$} & 1 & 52 & M & Nivolumab & Melanoma & Not available & $\begin{array}{l}\text { Steroids and } \\
\text { normal saline }\end{array}$ & $\begin{array}{l}\text { Resolved; } \\
\text { nivolumab } \\
\text { resumed }\end{array}$ \\
\hline & 2 & 73 & M & Pembrolizumab & Melanoma & Not available & Steroids & Improved \\
\hline
\end{tabular}

cases, immunotherapy resumed after kidney function improved. In the current case, nivolumab was permanently discontinued and the patient continued on a lengthy tapering course of steroids for approximately 4 months. Even after prolonged use of systemic corticosteroids and discontinuation of nivolumab, the immunologic anti-tumor effect appeared to persist and the tumors in his kidneys shrank in size. In the literature, there was a case of a melanoma patient who experienced continued tumor regression in spite of discontinuation of ipilimumab and daily administration of systemic corticosteroids for irAE [18]. In another case of a patient with melanoma treated with ipilimumab, both steroids and infliximab were used for grade 3 colitis, and there was no disease progression after approximately 3 years [19]. In a clinical trial, corticosteroids for treatment of irAE did not impact the clinical activity of ipilimumab in advanced melanoma patients [20].

In the current case, the possibility of post-infectious glomerulonephritis was raised based on glomerular deposits in the kidney biopsy. However, the patient did not have symptoms of pharyngitis or a skin infection prior to admission. Lack of hypertension and a normal C3 level were also not consistent with post-infectious glomerulonephritis. Autoimmune glomerular injury was determined as a major component of the etiology in our case, based on the temporal relationship between the use of nivolumab and the onset of AKI. To the best of the authors' knowledge, this is the first case of nivolumab-associated glomerulonephritis confirmed by light and electron microscopic findings.

The patient in our case was twice admitted with unexplained SIRS. Both hospitalizations occurred while on a decreasing dose of prednisone. After extensive diagnostic testing for infection, there was no clear source of SIRS. Pyrexia has been reported as a side effect of immunotherapy in clinical trials, but our patient had severe SIRS with hypotension requiring admission to the intensive care unit. Although the potential relationship between immunotherapy and SIRS is intriguing, more evidence is required before a causal link can be established.

In summary, use of systemic corticosteroids has been generally successful in achieving an optimal treatment response for immunotherapy-associated renal dysfunction. Nivolumab manufacturer recommends $0.5-1 \mathrm{mg} /$ $\mathrm{kg}$ /day prednisone equivalents for grade 2 or 3 renal dysfunction, and if no improvement occurs, $1-2 \mathrm{mg} / \mathrm{kg} /$ day prednisone equivalents and discontinuation of nivolumab. For life-threatening grade 4 renal dysfunction, the recommendation is to start with $1-2 \mathrm{mg} / \mathrm{kg} /$ day prednisone equivalents and permanently discontinue nivolumab [6]. Based on our experience, a pulse dose of steroids can be used for resistant renal dysfunction. Although treatment responses may not be ostensible initially, a presumptive decision of treatment failure should be avoided. As in our case, patients may require a prolonged course of systemic corticosteroids and 
hemodialysis, and kidney function may improve months later.

\section{Abbreviations}

AKI: Acute kidney injury; irAE: Immune-related adverse events; PD1: Programmed death 1; PDL1: PD ligand 1; SIRS: Systemic inflammatory response syndrome

\section{Acknowledgements}

No acknowledgements. There was no financial support or funding for this case report.

\section{Funding}

None.

\section{Availability of data and materials}

The dataset supporting the conclusions of this article is available in the Zenodo repository, doi:10.5281/zenodo.55295; https://zenodo.org/ record/55295.

\section{Authors' contributions}

MB managed longitudinal care of the patient. KJ contributed to inpatient care during admissions. XZ reported on light microscopy and electron microscopy examinations. $\mathrm{KJ}$ wrote the first draft of the manuscript. MB and $\mathrm{XZ}$ provided revisions and $\mathrm{KJ}$ wrote the final version of manuscript. All authors read and approved the final version of manuscript.

\section{Competing interests}

The authors declare that they have no competing interests.

\section{Consent for publication}

Written informed consent was obtained from the patient for publication of this case report.

\section{Ethics approval and consent to participate}

This study was exempted from institutional review board approval because it was a case review and secondary analysis.

\section{Author details}

Department of Medicine, Fox Chase Cancer Center, 333 Cottman Ave, Philadelphia, PA 19111, USA. ²Department of Pathology and Laboratory Medicine, Lewis Katz School of Medicine, Temple University, 3500N Broad St, Philadelphia, PA 19140, USA. ${ }^{3}$ Department of Medical Oncology, Fox Chase Cancer Center, 333 Cottman Ave, Philadelphia, PA 19111, USA.

Received: 10 June 2016 Accepted: 15 November 2016

Published online: 22 November 2016

\section{References}

1. Schadendorf D, Hodi FS, Robert C, Weber JS, Margolin K, Hamid O, Patt D, Chen TT, Berman DM, Wolchok JD. Pooled analysis of of long-term survival data from phase II and phase III trials of ipilimumab in unresectable or metastatic melanoma. J Clin Oncol. 2015:33(17):1889-94.

2. Wolchok JD, Kluger H, Callahan MK, Postow MA, Rizvi NA, et al. Nivolumab plus ipilimumab in advanced melanoma. N Engl J Med. 2013;369(2):122-33.

3. Champiat S, Lambotte O, Barreau E, Belkhir R, Berdelou A, Carbonnel F, et al. Management of immune checkpoint blockade dysimmune toxicities: a collaborative position paper. Ann Oncol. 2016;27(4):559-74.

4. Francisco LM, Salinas VH, Brown KE, Vanguri VK, Freeman GJ, Kuchroo VK Sharpe AH. PD-L1 regulates the development, maintenance, and function of induced regulatory T cells. J Exp Med. 2009;206(13):3015-29.

5. Amarnath S, Mangus CW, Wang JC, Wei F, He A, Kapoor V, et al. The PDL1PD1 axis converts human TH1 cells into regulatory T cells. Sci Transl Med. 2011;3(111):111-20.

6. Opdivo (Nivolumab). http://packageinserts.bms.com/pi/pi_opdivo.pdf. Last Accessed 27 May 2016

7. Spain L, Diem S, Larkin J. Management of toxicities of immune checkpoint inhibitors. Cancer Treat Rev. 2016:44:51-60.

8. Borghaei H, Paz-Ares L, Horn L, Spiegel DR, Steins M, Ready NE, et al. Nivolumab versus docetaxel in advanced nonsquamous non-small-cell lung cancer. N Engl J Med. 2015;373(17):1627-39
9. Robert C, Schachter J, Long GV, Arance A, Grobb JJ, Mortier L, et al. Pembrolizumab versus ipilimumab in advanced melanoma. N Engl J Med. 2015;372(26):2512-32.

10. Hamid O, Robert C, Daud A, Hodi FS, Hwu WJ, Kefford R, et al. Safety and tumor responses with lambrolizumab (Anti-PD-1) in melanoma. N Engl J Med. 2013;369(2):134-44.

11. Fadel F, Karoui KE, Knebelmann B. Anti-CTLA4 antibody-induced lupus nephritis. N Eng J Med. 2009;361(2):211-2

12. Forde PM, Rock K, Wilson G, O'Byrne KJ. Ipilimumab-induced immunerelated renal failure - A case report. Anticancer Res. 2012;32(10):4607-8.

13. Voskens CJ, Goldinger SM, Loquai C, Robert C, Kaehler KC, Berking C, Bergmann T, Bockmeyer $\mathrm{CL}$, et al. The price of tumor control: an analysis of rare side effects of anti-CTLA-4 therapy in metastatic melanoma from the ipilimumab network. PLoS One. 2013;8(1):e53745. doi:10.1371/journal. pone.0053745

14. Izzedine H, Guetin V, Gharbi C, Mateus C, Robert C, Routier E, et al. Kidney injuries related to ipilimumab. Invest New Drugs. 2014;32:769-73.

15. Thajudeen B, Madhrira M, Bracamonte E, Cranmer LD. Ipilimumab granulomatous interstitial nephritis. Am J Ther. 2015;22(3):e84-7. doi:10. 1097/MJT.0b013e3182a32ddc.

16. Vandiver JW, Singer Z, Harshberger C. Severe hyponatremia and immune nephritis following an initial infusion of nivolumab. Target Oncol. 2000; doi: 10.1007/s11523-016-0426-9.

17. Hofmann L, Forschner A, Loquai C, Goldinger SM, Zimmer L, Urqurel S, et al. Cutaneous, gastrointestinal, hepatic, endocrine, and renal side-effects of anti-PD-1 therapy. Eur J Cancer. 2016; doi: 10.1016/j.ejca.2016.02.025.

18. Harmankaya K, Erasim C, Koelblinger C, Ibrahim R, Hoos A, Pehamberger H, Binder M. Continuous systemic corticosteroids do not affect the ongoing regression of metastatic melanoma for more than two years following ipilimumab therapy. Med Oncol. 2011;28:1140-4

19. Arriola E, Wheater M, Krisnan R, Smart J, Foria V, Ottensmeier C Immunosuppression for ipilimumab-related toxicity can cause pneumocystis pneumonia but spare antitumor immune control. Oncoimmunology. 2015: 4(1):e1040218. doi:10.1080/2162402X.2015.1040218

20. Amin A, Depril V, Hamid O, Wolchok J, Maio M, Neyns B, et al. Evaluation of the effect of systemic corticosteroids for the treatment of immune-related adverse events (irAEs) on the development of maintenance of ipilimumab clinical activity. J Clin Oncol. 2009;27:abstr 9037.

\section{Submit your next manuscript to BioMed Central and we will help you at every step:}

- We accept pre-submission inquiries

- Our selector tool helps you to find the most relevant journal

- We provide round the clock customer support

- Convenient online submission

- Thorough peer review

- Inclusion in PubMed and all major indexing services

- Maximum visibility for your research

Submit your manuscript at www.biomedcentral.com/submit
Biomed Central 